\title{
Current Processes of Digital Transformation of High-Tech Engineering Enterprises Economy
}

\author{
Vjatcheslav V. Nefedev 1*[ORCID 0000-0001-9277-0341], \\ Aleksandr A. Vershinin 1[ORCID 0000-0002-1563-8483], \\ Yanina V. Patturi 2[ORCID 0000-0001-8554-1567] \\ ${ }^{1}$ LEONOV Moscow Region University of Technology, Korolev, Russia \\ ${ }^{2}$ Yaroslav-the-Wise Novgorod State University, Veliky Novgorod, Russia \\ nefediev50@mail.ru
}

\begin{abstract}
Nowadays, a considerable number of production processes depends on the development of information technology. At the same time, almost every market participant has the opportunity to use digital transformation, which makes this process not only useful, but also affordable. At the same time, there is an increase in labor productivity and a decrease in costs, which, ultimately, positively affect the final cost of the manufactured product. It means that while maintaining the quality of products, an increase in its competitive advantage is achieved by reducing costs. An analysis of the available sources shows that Russia has a stable indicator in the global ranking of digital competitiveness, but its place is far from being the leading one. Obviously, there is an acute need to accelerate the digital transformation of the domestic economy. In this regard, in order to accelerate digital transformation, it is advisable to develop appropriate national regulatory legal acts. The article draws attention to the fact that with the full-scale introduction of the latest information technologies, systematic training of personnel will be required; a due respect should be paid to veteran workers. In the course of digital transformation, it is proposed to develop, first of all, a typical digital industrial platform of an enterprise, which could solve not only routine business processes of an enterprise, but also optimize management as a whole. For all the importance and relevance of the study of this problem, at present, the major statistical studies can be found mostly in the consulting agencies' reports and not in research literature. The article discusses the definitions of the digital economy and analyzes the tasks that can be solved using digital transformation, which is especially significant for high-tech engineering enterprises. The research resulted in developing recommendations for the digital transformation of high-tech engineering enterprises.
\end{abstract}

Keywords: digital economy of enterprises, digital transformation, high-tech engineering enterprises

\section{INTRODUCTION}

At the present stage of the world economy development, there is an increased interest in information technology, artificial intelligence (AI) technologies and Blockchain [1].

The post-industrial model for the development of world economic relations has proclaimed the acute need for the development of intellectual capital and the total digitalization of business processes' for the production of competitive products. It resulted in a large-scale economic turning point: such a radical evolution of the benefits production mechanism turned intangible assets and intellectual capital into a key source of added value production both for the economy as a whole and for individual enterprises in particular. Consequently, it caused a change of the competitive paradigm in national economies and the international economic dialogue of countries [2].

The digital transformation of enterprises gives birth to the digital economy. In 1995, N. Negroponte introduced the concept of the digital economy, and contrasted the production of traditional (material) goods and services with digital ones. He pointed to the advantages of the latter, namely, the absence of physical criteria, negligible material consumption, 
easy scalability, instant distribution and transfer of the company's results.

This is especially relevant for high-tech engineering enterprises. Currently, there is no generally accepted definition of the digital economy. This is due, firstly, to the relative novelty of this concept, and secondly, to its versatility and multidimensionality [3].

In Russia, according to the annual collection "Indicators of the Digital Economy: 2021", the digital economy is defined as the activity of creating, distributing and using digital technologies and related products and services [4].

In 2017, the "Strategy for the Development of the Information Society in the Russian Federation for 2017-2030" was developed and approved; there the digital economy is understood as an economic activity in which the key production factor is digital data, which being processed in large amount and analyzed, in comparison with traditional forms of management, allow for the significant increase in the efficiency of various types of production, technologies, equipment, storage, sale, delivery of goods and services [5].

Only a few decades ago, information technologies were not considered crucial for the successful development of an enterprise. But over time, the role of digitalization in the innovative development of enterprises, especially scienceintensive mechanical engineering, has grown and ceased to play only a supporting role of business processes [6].

According to some researchers, the process of digital transformation is going on at such an accelerated pace that theory does not keep up with practice. That is why there is so little theoretical research in open access and a huge amount of research is conducted by consulting agencies [7].

It should be assumed that the process of digital transformation of the economy will accelerate every year [8]. Thus, the need to analyze the situation in this area will increase. The results of research in this area will allow taking important and strategically correct decisions that will bring enterprises to a new level, open up new markets for them, and increase their competitiveness. First of all, it concerns hightech engineering enterprises.

\section{MATERIALS AND METHODS}

During the research, a comprehensive analysis of the theoretical aspects related to the digitalization of the economy of mechanical engineering enterprises was carried out, and the currently available statistical data on this issue were analyzed.

The following research tasks were solved:

- the available theoretical approaches to digital transformation at high-tech engineering enterprises have been studied;

- the statistical data of open sources on the digital transformation of high-tech engineering enterprises have been analyzed;

- measures to improve the digitalization processes of high-tech engineering enterprises are proposed.

The research method of observation and methods of statistical, regulatory and economic analysis were applied.

\section{RESULTS}

The digital transformation of the economy primarily concerns the consumer services market. The transformation process allows enhancing the competitiveness of products by raising the efficiency of both an individual enterprise and entire sectors of the economy. The increased state interest in the development of technologies is an integral factor that allows not only competing in the world market, but also becoming a forward in any industries.

At the moment, digital transformation in the domestic economy is slow-moving. This is due to the fact that not only implementation per se is necessary, but also the creation of a specific infrastructure for the smooth and efficient functioning of the entire system.

Tech giants can solve a number of problems with created digital platforms. One of the main ones is customer retention and link to equipment due to technological dependence. Digital expansion allows not only retaining, but also attracting new customers by creating accessibility and increased demand for their products. This situation helps the leading enterprises in the IT sector to expand production, and, consequently, to increase profits, part of which can be channeled to new developments and research related to innovations, thus maintaining the leadership positions [9].

This situation will also change the financial structure of expenses, namely, redistribute them. For example, if one could create a more precise accounting of existing stocks at the enterprise and reduce the costs of their storage, as well as reduce 
logistics costs, then one should increase the expenses on IT technologies, which helped to reduce the former expenses. This distribution of expenses will ultimately lead to the fact that world technology leaders will start receiving the same redistributed profits.

This situation will change the structure of the company's expenses. For example, applying the program for a more precise accounting of the available stocks at the enterprise, it is necessary to provide for the costs of purchasing the corresponding program. This redistribution of income is used by world technology leaders.

Ideally, the digital transformation of the enterprise economy should lead to turning each enterprise into a single information system. It will allow high-tech machine building enterprises to significantly reduce the cost of production and increase labor productivity. The solutions offered by digitalization should transform the chains of added value creation, increasing the efficiency of both separate parts and the entire enterprise as a whole.

In the course of digital transformation, enterprises solve the following tasks.

1) Reducing the cost, as well as increasing the reliability of the processes of collecting, storing, processing and disseminating information through the use of advanced achievements of digital technologies.

2) Reducing the flow time of the main and auxiliary business processes, which leads to a reduction in the cost of communication both within the enterprise itself and during its interaction with the external environment.

3) Improving equipment reliability. Digitalization helps to optimally configure the operating mode of equipment, to quickly monitor its condition and to report faults in time through the use of appropriate sensors.

4) Increasing production efficiency through the introduction of automated logistics systems. Simultaneously, the amount of stock and materials, as well as components and parts that are stored in the warehouse, can be optimized and significantly reduced. In addition, optimization of logistics goes on both inside the enterprise, by developing new or improving the existing routes for the movement of finished products and semi- finished products, and outside, by setting the correct priorities for logistics operations and automated control of loading and unloading vehicles.

5) Optimization of production processes. It is due to obtaining the necessary real time information about the state of the production process and for making management decisions.

6) Possibility to work with large structured or unstructured data arrays of considerable volume (Big Data) [10]. The increase of the hardware power, as well as the improvement of software will allow the development of software models necessary for the Big Data analysis.

7) Increased product quality. Product quality is one of the fundamental components of the effective development of any enterprise.

8) Improvement of technical and technological components of production systems. Digitalization allows using the latest technologies and developments in the field of industrial equipment. They will help not only optimize existing jobs, but also enter completely new areas of activity, and therefore increase the consumer value of the product.

9) Improving the level of labor safety. It becomes possible due to the digitalization of the production processes of the enterprise. Specialized information technologies are able to prevent dangerous situations in the workplace, to reduce the number of unsafe scenarios that can occur when employees move during their work.

Figure 1 presents the world ranking of digital competitiveness. The ranking is a comparative table, where the country with the highest level of digital competitiveness scores $100 \%$ (a benchmark for other ranked participants); while the country with the lowest score already varies depending on how far it lags behind the leading one.

According to the analysis, Russia has a stable indicator in the global ranking of digital competitiveness. The first four places are occupied by the USA, Singapore, Denmark and Sweden, respectively. Russia occupies the 42, 40, 38, 43 places for the period 2017-2020 respectively. In 2020, Russia, taking the 43rd place, was between Italy (42) and Turkey (44). 


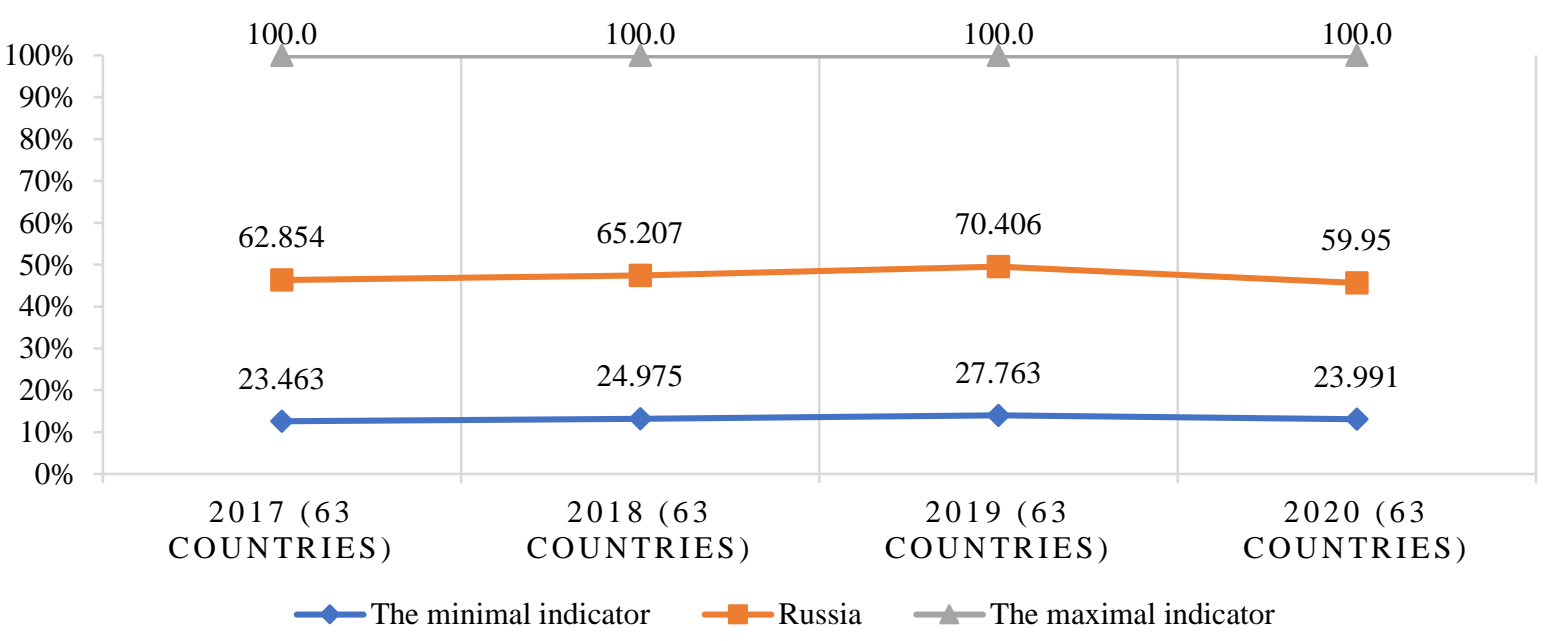

Figure 1. World Digital Competitiveness Ranking

Source: Compiled by the author based on the data [6]

In the course of digital transformation, a significant role should be given to the industrial platform that can be developed either by the enterprise itself or outsourced [11]. Such a platform should help with routine tasks that will allow the whole management process to be optimized. Online management of most processes from the procurement of raw materials to the delivery of the finished product to the final consumer will increase efficiency and also reduce the execution time of each process. The platform development will result in identification of unnecessary, duplicate or completely interfering processes in the spheres of purchase, production and further sale of the product. Its integration together with the digital

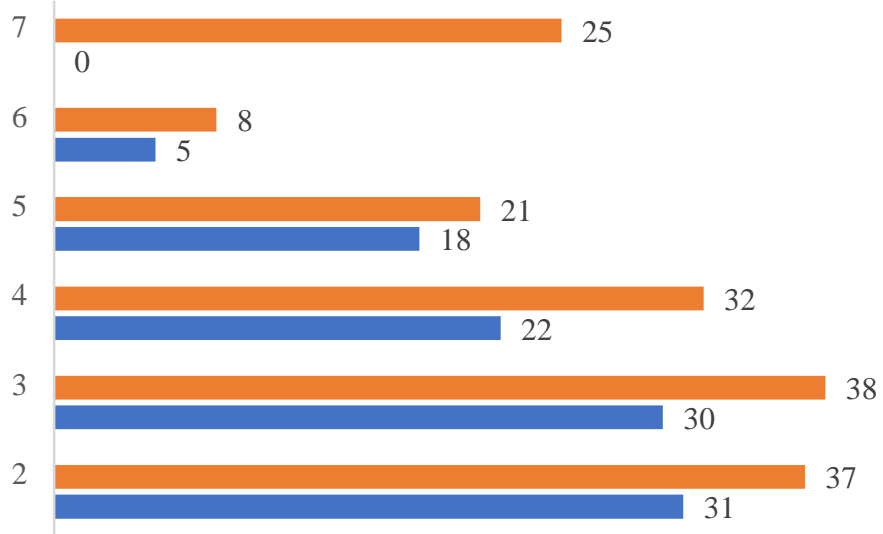

transformation creates groundwork for a further full transition to digitalization, from partial machine and robotic labor to complete labor.

Due to the total digital transformation, high-tech engineering enterprises can open up new markets that are currently inaccessible to them, because services and goods become more mobile. As a result of digitalization, the time from the purchase of raw materials and materials to the delivery of the product to the final customer is reduced significantly.

In 2019, the Higher School of Economics conducted a statistical analysis of the factors that hindered the digital transformation of enterprises; the data is presented in Figure 2.

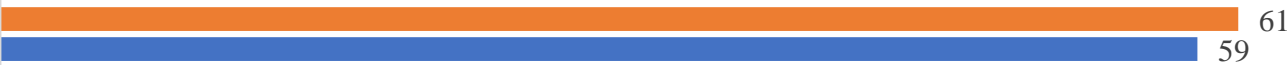

1 - Lack of sufficient budget

2 - Low level of readiness of production for digital transformation

3 - Lack of a developed digital strategy for the enterprise

4 - Low ROI on digital transformation

5 - Low level of digital literacy of staff

6 - Barriers to doing business

7 - Uncertainty of legal norms in the field of digitalization

Figure 2. Factors contributing to the slowdown in the development of enterprises' digitalization Source: Compiled by the author using the data [6]

The analysis was based on the estimates of managers of more than a thousand industrial enterprises [12]. More than $60 \%$ of respondents named the lack of the necessary budget to implement the desired tasks related to digital transformation as the main problem. Also, more than 
a third of respondents noted the absence of a clearly defined digitalization strategy. In addition to the lack of the required budget, one of the problems associated with finances was the low ROI allocated for digitalization. The presence of barriers and low digital literacy of staff had a lesser impact on digitalization.

In this regard, in order to improve the processes of digital transformation, it is necessary to provide for systematic training and professional development of staff in the field of digital technologies. This is relevant both for staff with existing work experience and for new young professionals.

In our opinion, firing elderly employees cannot be a solution to the problem of low staff competence in the field of IT technologies. This is due to the fact that very often departments or entire workshops are based on their knowledge and accumulated experience. Sometimes it is advisable, while retaining an experienced employee, to reduce his/her workload, giving him/her the position of a mentor.

It should be borne in mind that the redistribution of resources towards digitalization is inevitable. The reason is that all enterprises, high-tech engineering enterprises in particular, will definitely go through all the stages of the digital transformation of their production. Thus, it is necessary to quickly carry out activities for digital transformation and influence the processes associated with it at each enterprise. It will help quickly and painlessly survive changes in the market conditions.

\section{DISCUSSION}

Currently, the issues of digital transformation of high-tech engineering enterprises are rather acute; the analysis also shows that the relevance of these issues will only increase over time.

This trend is explained by the desire of enterprises to enhance labor productivity and increase profits, while reducing costs. The most effective tool in this case is the digital transformation of high-tech engineering enterprises.

Russia pays special attention to the sphere of IT technologies, but it is going on rather slow, since the bulk of information technologies is an export product. Some domestic IT companies are developing and are becoming competitors for foreign companies, but at present their number is small. Subsidizing and support at the state level contribute to their effective development. The import substitution program announced by the government is aimed at ensuring that domestic enterprises use primarily the products of domestic companies, which will allow them to significantly expand the domestic market.

The need to develop import substitution programs arose due to the impact of the external environment on Russia in general, and on high-tech engineering enterprises in particular. In this case, one should understand that the development of internal processes for digital transformation was caused not by the desire for internal development, but by the sanctions that were introduced against Russia by Western countries. There is a problem issue whether the response of domestic business to the information lag was timely and what caused this lag. It is the fact that in our country digitalization began suddenly and mostly under the pressure from outside.

It is also worth remembering that the most part of products sold by high-tech engineering enterprises is an object of medium and long-term planning. Thus, not all managers are ready to support investments in projects that will start yielding results and reach the break-even point much later. Business is primarily aimed at making a profit and preferably in the short term. Investing billions of rubles in digital transformation for potential volume and profit growth is not a motivating factor. This is due to the fact that the instability of the currency, the imperfection of the regulatory framework does not give confidence in a positive result in the long term.

As mentioned above, the development of digitalization and digital transformation of high-tech engineering enterprises requires the availability of IT standards, which are just beginning to appear in domestic legislation. Certain processes are not structured at all at the state level, which greatly inhibits the introduction of digital technologies.

\section{CONCLUSION}

Based on the results of the study, the following conclusions can be drawn. Digital transformation is an inevitable process for all enterprises, and the faster it happens, the more efficiently they will develop.

The theoretical aspects related to digital transformation were thoroughly studied during the research.

A statistical analysis of the open access data was carried out, which made it possible to identify the current state of domestic high-tech engineering 
enterprises. Obviously, we can conclude that at present, the Russian economy, in terms of the introduction of digital technologies, does not occupy a leading position. However, the position of the state in the development of its own technologies is moving into an active phase and creates the necessary prerequisites for a significant growth of domestic IT products.

\section{AUTHORS' CONTRIBUTIONS}

Vjatcheslav V Nefedev: general project management, analysis and additions to the text of the article. Aleksandr A. Vershinin, Yanina V. Patturi: collection and processing of materials, preparation of the initial version of the text.

\section{REFERENCES}

[1] R. Antolín-López, J. Martínez-del-Río, J. Céspedes-Lorente, "Fostering product innovation in new ventures: which public instruments are more effective?", European Research on Management and Business Economics, 2017, vol. 22(1), pp. 38-46. DOI: 10.1016/j.iedee.2015.05.002

[2] S.S. Serebrennikov, S.S. Kharitonov, "Technological transition from Industry 2.0 and 3.0 to Industry 4.0 in the industrial sector", Vestnik MIRBIS, 2020, vol. 4(24), pp. 67-79. (In Russ.). DOI: 10.25634/MIRBIS.2020.4.8

[3] S.Yu. Ozornin, N.G. Terlyga, "Challenges of digital transformation of enterprises: management perspective", Eurasian Union of Scientists, 2020, vol. 4(73), pp. 49-59. (In Russ.).

[4] Indicators of the Digital Economy: 2021 - HSE, 2021. (In Russ.). Retrieved from https://www.hse.ru/primarydata/ice2021

[5] Decree of the President of the Russian Federation No. 203 dated 09.05.2017 “On the Strategy for the Development of the Information Society in the Russian Federation for 20172030”, 2017. (In Russ.). Retrieved from http://www.kremlin.ru/acts/bank/41919

[6] V. Nissen, T. Lezina, A. Saltan, "The Role of IT-Management in the Digital Transformation of Russian Companies", Foresight and STI Governance, 2018, vol. 12(3), pp. 53-61. DOI: 10.17323/2500-2597.2018.3.53.61

[7] I.A. Arenkov, S.A. Smirnov, D.R. Sharafutdinov, D.V. Yaburova, "Transformation of the enterprise management system in the transition to the digital economy", Russian Journal of Entrepreneurship, 2018, vol. 19(5), pp. 1711-1722. (In Russ.). DOI: 10.18334/rp.19.5.39115

[8] A. Baiyere, H. Salmela, T. Tapanainen, "Digital transformation and the new logics of business process management", European Journal of Information Systems", 2020, vol. 29(3), pp. 238-259.

DOI: 10.1080/0960085X.2020.1718007

[9] N. Mgadmi, W. Moussa, A. Béjaoui, T. Sadraoui, A. Guachaoui, "Revisiting the nexus between digital economy and economic prosperity: evidence from a comparative analysis", Australian Journal of Telecommunications and the Digital Economy, 2021, vol. 9(2), pp. 69-90. DOI: 10.18080/JTDE.V9N2.384

[10]P. Mikalef, J. Krogstie, "Examining the interplay between big data analytics and contextual factors in driving process innovation capabilities", European Journal of Information Systems, 2020, vol. 29(3), pp. 260-287. DOI: 10.1080/0960085X.2020.1740618

[11]C. Peukert, "Determinants and heterogeneity of switching costs in it outsourcing: estimates from firm-level data", European Journal of Information Systems, 2019, vol. 28(6), pp. 291317. DOI: 10.1080 / 0960085X.2018.1529374

[12]I. Busnetty, T.T.H. Tambunan, "Gap between regions in the use of E-commerce by MSES", Australian Journal of Telecommunications and the Digital Economy, 2020, vol. 8(4), pp. 37-63. DOI: $10.18080 /$ jtde.v8n4.303 